\title{
COMPANIES CONFRONT FDA AND DEMONS WITHIN
}

Researchers lowering downstream-processing costs face several obstacles. The biggest is current technology's inability to fully characterize recombinant proteins. Analytical techniques can completely define the chemical nature of such traditional, low-molecular-weight drugs as penicillin. But because proteins are more complex compounds, these techniques can't define them as discrete chemical entities. To compensate, the U.S. Food and Drug Administration (FDA, Bethesda, MD) characterizes a protein by including the process that makes it. So changing the process changes the product. And a new product requires a new license.

This reasoning has made companies reluctant to change production processes, which creates problems. "The fundamental dilemma is that the engineers, who are concerned about scale up, are on the receiving end of a process conceived by a laboratory researcher, who doesn't really care if his process is scalable," says Robert Sitrin, director of biochemical process R\&D at Merck Sharp \& Dohme (West Point, PA). Sitrin adds that he's seen "people on the verge of fist fights" over proposed process changes. "They want to know over a stack of 100 bibles that it's the same product. But no one can change a process without potentially changing the product." Stuart Builder, a Genentech staff scientist, estimates that significantly changing a process for a licensed biologic takes two years and millions of dollars.

The key then is for companies to make process changes before FDA licenses a product. "As a rule of thumb, it's a good idea to have the process set by Phase III clinical trials," says an FDA scientist who requested anonvmity. Companies should identify the biochemical parameters that affect a product's clinical efficacy. They should aiso develop in vivo and in vitro assays to show that minor process changes don't compromise efficacy.

Communication is most im portant, though. Before making process changes, companies should discuss them with FDA. They should tell FDA why they're making a change and "why the change will have a minor impact on the product," says the FDA scientist. "If a change isn't discussed, all sorts of bells go off."

Within a company, communication between laboratory researchers and process engineers is essential. "If a downstream engineer waits for the whole broth to arrive on his doorstep to begin purification, he's missed some of his greatest opportunities," says Genentech's Builder. Once a molecular biologist sequences a gene for a target protein, even before the protein is expressed, information is available for an engineer to develop purification strategies. This includes the protein's size, sequence, composition, isoelectric point, and potential glycosylation sites. Engineers can also determine how fermentation media components will affect the protein, as well as how the components and protein will behave chromatographically.

Yet communication within a company isn't a given. "Researchers and engineers speak different languages and come from different cultures," says Gary Lorimer, a research leader in the central research \& development department at DuPont (Wilmington, DE). And Scott Wheelwright, manager of diagnostic protein purification at Chiron (Emeryville, CA), adds that "egos and personalities enter in. Everyone thinks their way's the best."

Communication between analytical-equipment manufacturers and FDA is also important. So reports Charles Cooney, a professor of chemical and biochemical engineering at the Massachusetts Institute of Technology (MIT, Cambridge), in an unpublished survey of company executives and FDA officials entitled The Advancement of Analytical Techniques and Their Impact on TherapeuticProtein Approval. FDA requires only that an analytical technique reproducibly detects whether the product of a production process meets specifications. "FDA stands as the ultimate authority over whether industry accepts and thus widely uses a technique," says the survey. "It has the potential to discourage industry's acceptance of new techniques. However, according to those interviewed at the FDA's Center for Biologics, new techniques "do not bother them.

Manufacturers that familiarize FDA with their new products gain two advantages, the survey reports. Since FDA has an industry-wide view, it can give manufacturers suggestions on how to improve their products, as well as suggestions on what the industry is looking for. Secondly, after FDA views a manufacturer's technique, it might suggest it to a company that has run into production problems while seeking FDA marketing approval.

Other survey findings include:

-Giving the "right numbers reproducibly" is the quality companies want most from an analytical technique. Speed, cost, and sensitivity are lower priorities.

- Sixty percent of company executives approach new analytical techniques with caution.

-The next advance in analytical techniques will involve analysis of protein glycosylation structures.

-FDA will raise its limit of 10 picograms/dose of DNA within five years, once it has received adequate data on the safety of higher DNA levels. membrane affinity separations, however, allow an affinity step right after bioreactor harvesting, eliminating concentration and partial-purification steps. This reduces overall processing time and improves total yield, since about 10 percent of product is lost at each step.

Take, for example, a protein-A membrane used to purify a mouse IgG monoclonal antibody from serumcontaining medium. Staphylococci-derived protein A specifically binds IgGs, of course. In 15 minutes, a module with a 10-milliliter membrane matrix volume purified 1.2 liters of crude monoclonal, with a 97 percent yield, reports Sepracor. Analysis showed removal of 95 percent of contaminating nucleic acids and over 99.5 percent of bovine serum albumin. It found 11 parts per million of leached protein A.

Efficient use of ligand is shown in another Sepracor protein A-IgG experiment. Results showed that $\$ 300$ of protein A could purify $\$ 80,000$ of IgG monoclonal antibody. "Extrapolating these findings suggests that using expensive ligands will eventually prove practical even for lower-value products like BST," says Yves Fouron, Sepracor's vice president of business development.

\section{Protein Refolding}

Another approach to cutting downstream-processing costs involves improvement of protein refolding. Bacterial production of recombinant proteins, particularly mammalian proteins, often results in inactive species of the proteins forming inclusion bodies. Processing must separate the inclusion bodies from other cell components then solubilize them to unfold the protein. Yet during refolding, the protein may reaggregate, reducing the yield of active protein and further complicating the purification process.

A method that uses polyethylene glycol (PEG) to minimize aggregate formation during refolding is being developed by Daniel Wang, director of MIT's Biotechnology Process Engineering Center. MIT has applied for a patent on the work. Wang is currently collaborating with four companies to see if the technique improves refolding of gamma interferon and other therapeutic proteins.

Wang studied carbonic anhydrase B (CAB), a protein with a well-understood refolding pathway. By adding 3 grams/liter PEG to an aqueous solution containing $\mathrm{CAB}$ inclusion bodies, Wang increased CAB's normal refolding rate three fold. He believes PEG stabilizes the first intermediate in the $\mathrm{CAB}$ refolding pathway. This intermediate is likely a globule structure with hydrophobic surface regions. PEG sta- 